\title{
EDITORIAL
}

\section{A new era of addiction treatment amplifies the stigma of disease and treatment for individuals with obesity}

International Journal of Obesity (2016) 40, 1335-1336; doi:10.1038/ ijo.2016.101; published online 21 June 2016

Case: a female patient at the Mass General Weight Management Center presented for a telephone consultation. She reported distress arising from a bariatric preoperative evaluation during which she was characterized as a drug addict because of her medication history that included naltrexone. The drug was prescribed in combination with bupropion to treat her obesity, not a drug or alcohol addiction.

Obesity, characterized by excess adiposity and typically with a body mass index $(B M I) \geqslant 30 \mathrm{~kg} \mathrm{~m}^{-2}$, is the most prevalent chronic disease in the United States, affecting about $38 \%$ of adults aged 20 years and over. An additional $33 \%$ of American adults are overweight, as judged by a BMI of $25.0-29.9 \mathrm{~kg} \mathrm{~m}^{-2}$. The prevalence of obesity has increased markedly since 1980 and has become a major public health concern. ${ }^{2}$ In addition to its adverse effects on quality of life, obesity increases the risk of cardiovascular disease, type 2 diabetes, several cancers and other conditions associated with increased mortality. ${ }^{2-4}$

Despite the growing epidemic of obesity, individuals with this disease often are stigmatized and experience disrespectful treatment in the healthcare system because of their body weight. $^{5}$ It is not uncommon, for example, for physicians and other healthcare professionals to hold negative attitudes toward individuals with obesity and for these individuals to be subjected to multiple forms of prejudice and discrimination..$^{5-8}$ In a study of $\sim 620$ primary care physicians, Foster et al..$^{9}$ reported that $>50 \%$ of them viewed individuals with obesity as being lazy, sloppy, and lacking of strong will and determination. Other studies from England, France and Australia have reported physicians with similar stereotyping of individuals with obesity. ${ }^{10-12}$

Another common stigma in the healthcare system is the stigma among healthcare professionals toward patients with substance use disorders. ${ }^{13}$ Healthcare professionals generally have negative attitudes toward patients with substance abuse or those who are receiving treatment for drug addiction. These patients are generally perceived as individuals who are manipulative, violent and with poor motivation. ${ }^{13-17}$ In these individuals, discrimination and alienation were both associated with poorer mental health and physical health. ${ }^{13}$

Public interest in the concept of food addiction has been growing and prompted research into potential stigma arising from labeling people with obesity as food 'addicts'. ${ }^{18}$

Because of the growing epidemics of both obesity and substance use disorder, several agents have been introduced to the market for the treatment of these diseases. Pharmacotherapy, in particular, is approved by the Food and Drug Administration (FDA) for individuals with a $\mathrm{BMI} \geqslant 30 \mathrm{~kg} \mathrm{~m}^{-2}$ (or with $\mathrm{BMI} \geqslant 27 \mathrm{~kg} \mathrm{~m}^{-2}$ with associated comorbidities) for whom behavioral treatment alone is inadequate. ${ }^{19}$ Bupropion/naltrexone extended release combination therapy (Contrave, Orexigen Therapeutics, Inc., La Jolla, CA, USA) is a drug that was approved by the FDA in September 2014 for obesity treatment. ${ }^{20}$ The combination therapy produces weight loss by increasing the rate of firing of proopiomelanocortin neurons, leading to appetite suppression. $^{21}$ Phase III trials revealed an approximate $4.5 \%$ greater weight loss at 1 year compared with placebo. ${ }^{20,22,23}$ In the largest study of Contrave (Orexigen Therapeutics, Inc.), 48\% of medication-treated vs $16 \%$ of placebo-treated participants lost $\geqslant 5 \%$ of initial weight. ${ }^{22}$ Physicians also use either generic bupropion, naltrexone or the combination of both drugs for treatment of obesity.

Extended release of naltrexone, a mu-opioid receptor antagonist, was also approved by the FDA in 2010 for use in the treatment of individuals with substance use disorder to prevent opioid relapse in this group. ${ }^{24,25}$ The use of naltrexone in this group of patients is a particularly appealing option because of its efficacy and because it is a noncontrolled substance with no known abuse potential. ${ }^{24,25}$

The utilization of naltrexone in the treatment of both obesity and addiction may lead to the mistaken attribution of drug addiction in individuals receiving treatment for obesity. This may result in amplifying the stigma burden for individuals with obesity, rendering this subgroup of patients vulnerable to stereotyping, bias and discrimination, which makes stigma-driven problems even worse. For a group that already faces discrimination secondary to excess weight, it is quite troubling that they may be subjected to suffering from more severe discrimination secondary to taking a drug that will treat their condition and help them to achieve a healthy weight.

Earlier this year, president Obama announced that addressing the opioid and heroin epidemic is a priority for his administration. In his announcement, the president proposed a $\$ 1.1$ billion initiative in new funding to combat this growing epidemic. This new initiative will expand access to treatment for individuals with opioid dependence, which will most likely exacerbate the stigmatization of individuals with obesity receiving therapies containing naltrexone for the treatment of their disease. This stigmatization may result in catastrophic consequences, including but not limited to, negative responses, feeling of powerlessness, maladaptive eating behaviors, exercise avoidance, less adherence to treatment and reduced motivation to lose weight. ${ }^{6}$

Therefore, we recommend that healthcare professionals prescribing naltrexone, either on its own or as part of a combination therapy for obesity, involve their patients in the treatment decision and educate them about the different uses of the medication. When prescribing this medication, they should explain the indication of use for obesity. In addition, physicians prescribing these medications should clearly document the indications for use of this particular pharmacotherapy in the treatment of obesity to prevent any possible stigmatization by other healthcare workers of individuals with obesity receiving naltrexone for therapy. We further recommend expanded efforts to educate healthcare professionals, who are all increasingly caring for patients with obesity, about the harmful effects of implicit bias and stigma toward people with obesity.

\section{CONFLICT OF INTEREST}

The authors declare no conflict of interest.

N Alfaris ${ }^{1,2,3}$, TK Kyle ${ }^{4,5}$, J Nadai ${ }^{1,3}$ and FC Stanford ${ }^{1,3,6}$ ${ }^{1}$ MGH Weight Center, Department of Medicine- Gastrointestinal Unit, Massachusetts General Hospital, Boston, MA, USA; 
1336

${ }^{2}$ Department of Medicine-Gastrointestinal Unit, Obesity, Metabolism and Nutrition Institute, Massachusetts General Hospital,

Boston, MA, USA;

${ }^{3}$ Department of Medicine, Harvard Medical School Boston, Boston,

MA, USA;

${ }^{4}$ ConscienHealth, Pittsburgh, PA, USA;

${ }^{5}$ Obesity Action Coalition, Tampa, FL, USA and

${ }^{6}$ Department of Pediatrics Endocrinology, Massachusetts General Hospital, Boston, MA, USA

E-mail: nalfaris@mgh.harvard.edu

\section{REFERENCES}

1 World Health Organization. Obesity: preventing and managing the global epidemic. No. 894. World Health Organization, 2000.

2 Flegal KM, Carroll MD, Kit BK, Ogden CL. Prevalence of obesity and trends in the distribution of body mass index among US adults, 1999-2010. JAMA 2012; 307: 491-497.

3 National Task Force on the Prevention and Treatment of Obesity. Overweight, obesity, and health risk. Arch Intern Med 2000; 160: 898-904.

4 James WP. The epidemiology of obesity: the size of the problem. $J$ Intern Med 2008; 263: 336-352.

5 Mold F, Forbes A. Patients' and professionals' experiences and perspectives of obesity in health-care settings: a synthesis of current research. Health Expect 2013; 16: 119-142.

6 Puhl RM, Heuer CA. The stigma of obesity: a review and update. Obesity (Silver Spring) 2009; 17: 941-964.

7 Sabin JA, Marini M, Nosek BA. Implicit and explicit anti-fat bias among a large sample of medical doctors by BMI, race/ethnicity and gender. PLoS One 2012; 7: e48448.

8 Sutin A, Robinson E, Daly M, Terracciano A. Weight discrimination and unhealthy eating-related behaviors. Appetite 2016; 102: 83-89.

9 Foster GD, Wadden TA, Makris AP, Davidson D, Sanders RS, Allison DB et al. Primary care physicians' attitudes about obesity and its treatment. Obes Res 2003; 11: 1168-1177.

10 Bocquier A, Paraponaris A, Gourheux JC, Lussault PY, Basdevant A, Verger P. Obesity management knowledge, attitudes and practices of general practitioners in southeastern France; results of a telephone survey. Presse Med 2005; 34: 769-775.

11 Campbell K, Engel H, Timperio A, Cooper C, Crawford D. Obesity management: Australian general practitioners' attitudes and practices. Obes Res 2000; 8: 459-466.

12 Harvey EL, Hill AJ. Health professionals' views of overweight people and smokers. Int J Obes Relat Metab Disord 2001; 25: 1253-1261.
13 Ahern J, Stuber J, Galea S. Stigma, discrimination and the health of illicit drug users. Drug Alcohol Depend 2007; 88: 188-196.

14 Brener L, von Hippel W, Kippax S. Prejudice among health care workers toward injecting drug users with hepatitis $\mathrm{C}$ : does greater contact lead to less prejudice? Int J Drug Policy 2007; 18: 381-387.

15 Carroll J. The negative attitudes of some general nurses towards drug misusers. Nurs Stand 1995; 9: 36-38.

16 Howard V, Holmshaw J. Inpatient staff perceptions in providing care to individuals with co-occurring mental health problems and illicit substance use. $J$ Psychiatr Ment Health Nurs 2010; 17: 862-872.

17 Luoma JB, Twohig MP, Waltz T, Hayes SC, Roget N, Padilla M et al. An investigation of stigma in individuals receiving treatment for substance abuse. Addict Behav 2007; 32: 1331-1346.

18 DePierre JA, Puhl RM, Luedicke J. A new stigmatized identity? Comparisons of a "food addict" label with other stigmatized health conditions. Basic Appl Soc Psych 2013; 35: 10-21.

19 Executive summary: Guidelines. (2013) for the management of overweight and obesity in adults: a report of the American College of Cardiology/American Heart Association Task Force on Practice Guidelines and the Obesity Society published by the Obesity Society and American College of Cardiology/American Heart Association Task Force on Practice Guidelines. Based on a systematic review from the The Obesity Expert Panel, 2013. Obesity (Silver Spring) 2014; 22(Suppl 2): S5-S39.

20 Apovian CM, Aronne L, Rubino D, Still C, Wyatt H, Burns $\mathrm{C}$ et al. A randomized, phase 3 trial of naltrexone SR/bupropion SR on weight and obesity-related risk factors (COR-II). Obesity (Silver Spring) 2013; 21: 935-943.

21 Greenway FL, Whitehouse MJ, Guttadauria M, Anderson JW, Atkinson R, Fujioka K et al. Rational design of a combination medication for the treatment of obesity. Obesity (Silver Spring) 2009; 17: 30-39.

22 Greenway FL, Fujioka K, Plodkowski RA, Mudaliar S, Guttadauria M, Erickson J et al. Effect of naltrexone plus bupropion on weight loss in overweight and obese adults (COR-I): a multicentre, randomised, double-blind, placebo-controlled, phase 3 trial. Lancet 2010; 376: 595-605.

23 Wadden TA, Foreyt JP, Foster GD, Hill JO, Klein S, O'Neil PM et al. Weight loss with naltrexone SR/bupropion SR combination therapy as an adjunct to behavior modification: the COR-BMOD trial. Obesity (Silver Spring) 2011; 19: $110-120$.

24 Comer SD, Sullivan MA, Yu E, Rothenberg JL, Kleber HD, Kampman K et al. Injectable, sustained-release naltrexone for the treatment of opioid dependence: a randomized, placebo-controlled trial. Arch Gen Psychiatry 2006; 63: 210-218.

25 Lee JD, Friedmann PD, Kinlock TW, Nunes EV, Boney TY, Hoskinson RA et al. Extended-release naltrexone to prevent opioid relapse in criminal justice offenders. N Engl J Med 2016; 374: 1232-1242. 